\title{
Fast detection of genetic information by an optimized PCR in an interchangeable chip
}

\author{
Jinbo Wu ${ }^{\mathrm{a}}$, Rimantas Kodzius ${ }^{\mathrm{b}}$, Kang Xiao ${ }^{\mathrm{c}}$, Jianhua Qin ${ }^{\mathrm{d}}$ and Weijia Wen ${ }^{\mathrm{a}, \mathrm{b} *}$ \\ ${ }^{a}$ Nano Science and Nano Technology program and Physics Department, The \\ Hong Kong University of Science and Technology, Clear Water Bay, Hong Kong. \\ ${ }^{b}$ KAUST-HKUST Micro/Nanofluidic Joint Laboratory, The Hong Kong \\ University of Science and Technology, Clear Water Bay, Hong Kong. \\ ${ }^{c}$ Department of Biology, The Hong Kong University of Science and Technology, \\ Clear Water Bay, Hong Kong. \\ ${ }^{d}$ Dalian Institute of Chemical Physics, Chinese Academy of Sciences, 457, \\ Zhongshan Road, 11603, China
}

* Corresponding author. Tel.: 852 23587979; fax: 852 23581652; e-mail: phwen@ust.hk

Abstract: In this paper, we report the construction of a polymerase chain reaction (PCR) device for fast amplification and detection of DNA. This device consists of an interchangeable PCR chamber, a temperature control component as well as an optical detection system. The DNA amplification happens on an interchangeable chip with the volumes as low as $1.25 \mu$, while the heating and cooling rate was as fast as $12.7^{\circ} \mathrm{C} /$ second ensuring that the total time needed of only 25 minutes to complete the 35 cycle PCR amplification. An optimized PCR with two-temperature approach for denaturing and annealing $\left(\mathrm{T}_{\mathrm{d}}\right.$ and $\left.\mathrm{T}_{\mathrm{a}}\right)$ of DNA was also formulated with the PCR chip, with which the amplification of male-specific sex determining region Y (SRY) gene marker by utilizing raw saliva was successfully achieved and the genetic identification was in-situ detected right after PCR by the optical detection system.

Keywords: Point-of-Care Testing $\cdot$ Molecular diagnostics $\cdot$ Polymerase chain reaction $(P C R) \cdot$ Microfluidic Chip 


\section{Introduction}

Over the past few decades, microfluidic or lab-on-a-chip (LOC) systems have been demonstrated to have great potential to create portable point-of-care (POCT) medical diagnostic devices. Such devices can be designed to obtain and process measurements automatically from small volumes of complex fluids with advanced efficiency and speed(Yager et al. 2006). Among the microfluidic applications on POCT, the development of PCR-based POCT devices has gained much of attention(Daar et al. 2002; Mahalanabis et al. 2010; Sia and Kricka 2008). Such kind of devices can extract the genetic material (the DNA or RNA), amplify by PCR and detect - all in one box, and in very short time duration. The detection of DNA and its variation is critical for many fields, including clinical and veterinary diagnostics, industrial and environmental testing, and forensic science. Disease diagnosis and prognosis are based on effective detection of disease conditions (e.g. cancer), infectious organisms (e.g. HIV) and genetic markers. Diseases caused by infectious bacterial and viral DNA can be detected by PCR. PCR's high sensitivity enables virus detection soon after infection and even before the onset of disease. In most microfluidics applications, the DNA is first purified from tissues or bodily fluids (whole blood, serum, saliva, urine, stool, cerebral spinal fluid, tissues and cells) preparatory to PCR. DNA purification is performed before loading onto the chip or as an additional step incorporated into microfluidics design(Chen et al. 2007; Lien et al. 2009; Ng et al. 2004). There are some reports of successful amplification directly from blood or saliva(Park et al. 2008). Such non-invasive methods are preferable as they are direct and fast. By careful selection of suitable components and conditions, we succeeded in formulating a simplified and optimized PCR condition for DNA amplification utilizing raw saliva.

The integration of all functions into one chip is not only very difficult technically, but also raises the overall costs of the chip and the assay. At the same time, PCR has a major limitation of risk of cross-contamination. To minimize this risk, PCR chips are always disposable. The disposing of integrated chip leads to a lot of waste in resource though there are some functional parts, such as expensive metals like platinum (Pt) heater and thermal sensor which still can be reusable. Performing PCR in microfluidic chip has advantages such as smaller sample volume along with a higher heat-transfer rate. However, the possible evaporation-induced liquid loss may result in insufficient PCR product for the detection. To avoid it, integrated chips reported so far have used mineral oils(Anderson et al. 2000; Khandurina et al. 2000; Lagally et al. 2000; Lagally et al. 2001; Lee et al. 2004; Waters et al. 1998), tape(Zhao et al. 2003), Bostik’s Blu-Tacksilicone (Yeung et al. 2008), rubber gaskets(Yoon et al. 2002), microvalves(Lagally et al. 2001; Lagelly et al. 2004; Ramalingam et al. 2009), and long narrow diffusion channels(Wang et al. 2008). All of them need extra materials to provide physical confinement or extra channel structure.

In this work, rather than integrating more functions into one chip, we designed PCR device consisting of a temperature control system, an optical detection system and an interchangeable (disposable or modular) PCR chip, where the PCR chip is independent from the two functional systems. To minimize the evaporation-induced liquid loss, the interchangeable PCR chip was 
designed to be sealed by the heater directly, eliminating additional manual operations or complicated structures. The heating and cooling rate was as high as $12.7^{\circ} \mathrm{C} /$ second. As a result, SRY gene was successfully amplified in our chip within 25 min using the optimized condition. Genetic identification was detected right after PCR using raw saliva as template by the optical detection system.

\section{Experimental}

\subsection{Chip design, Fabrication and Layout}

The PCR chip is composed of silicon (double-side polished, $<100>$ ) and Pyrex glass layers with thickness of 400 and $500 \mu \mathrm{m}$ respectively. The PCR chamber on the silicon was formed with dry etching method. Afterward, two holes serving as the inlet and outlet of the PCR solution were drilled in the silicon substrate. The silicon substrate was then put into $900{ }^{\circ} \mathrm{C}$ 's furnace to grow $300 \mathrm{~nm}$ 's silicone dioxide on the surface for passivation and bonded to glass substrate by anodic bonding at last. Then the bonded full wafer was cut into pieces of chip. As can be seen from the PCR chip’s upper top view in Fig. 1A, the silicon and glass substrates were fully bonded together.

Pt thermal sensor and heater on the heater chip was fabricated by lift-off process on a silicon substrate (double-side polished, $<100>$ ) coated with $3 \mu \mathrm{m}$ thermal silicon oxide for electrical insulation. The back-side view of heater chip is shown in Fig. 1B. The inset is a full view (not to scale) of Pt thermal sensor. The Pt heater was designed to be $2 \mathrm{~mm}$ in width to form a low electrical resistance ( $22 \Omega$ in room temperature) for fast heating. On the contrary, the Pt thermal sensor is narrow and small (20 $\mu \mathrm{m}$ in width), for fast thermal response and has a higher electrical resistance (363 $\Omega$ in room temperature) for precise correlation to temperature. An enlarged partial view is shown in Fig. S4A. The heater chip was fixed onto an in-house made holder (Fig. S4B) by a press plate. When performing PCR, the PCR chip was attached tightly on the top-side of heater chip which can be realized by snuggling them each other with two press plates.

\subsection{Temperature Control}

To obtain high-precision temperature control with effective heating and cooling rates, the temperature control system shown in the lower pannel of Fig. 1, custom-designed and constructed in this work, was used. A multimeter (Agilent 34401A, 6 1/2 Digit Multimeter) to measure electrical resistance of thermal sensor, while a solenoid valve (V290, Shinyeong Mechatronics Co., Ltd.) was used to control on-off state of compressed air during cooling process. The heater is controlled by a DC power supply which is connected to a data acquisition card (National Instrument PCI-6259) to obtain the analogue signal used to control the solenoid valve and DC power supply, respectively. A personal computer (PC) with Labview program (National Instruments, Texas, USA) is used for connecting all the other devices and data processing. The resistance of Pt thermal sensor measured by the multimeter is converted to temperature degree 
under the calibrated resistance-temperature relationship in Labview program. A PID (proportional-integral-derivative) controller in the Labview program used to calculate the output current to the heater based on the error between the set temperature $\left(T_{s}\right)$ and the measured temperature $\left(\mathrm{T}_{\mathrm{ms}}\right)$. If $\mathrm{T}_{\mathrm{ms}}$ is lower than $\mathrm{T}_{\mathrm{s}}$, an electrical current will be applied to the heater until $\mathrm{T}_{\mathrm{ms}}=\mathrm{T}_{\mathrm{s}}$. For best performance, the PID parameters used in the calculation were tuned in this temperature control system. The PID controller calculation involves three separate parameters: the proportional, the integral and derivative values, denoted as P, I, and D. In this work, we used manual method to tune these three parameters one by one. To control the reaction time precisely at $T_{d}$ and $T_{a}$, a state machine (Fig. S5A) was set up in Labview program for cycling $T_{s}$, so that $T_{m s}$ will follow $\mathrm{T}_{\mathrm{s}}$ loop until the state machine finish the set cycles and DNA will be amplified after certain thermal cycles. To obtain a fast cooling rate, the compress air is used to cool down the heater to a certain assigned temperature via a solenoid valve.

\subsection{Optical Detection}

As illustrated in the upper pannel of Fig. 1, the optical detection system consists of a blue LED (MBLED, 625mW, Thorlabs), a filter cube (U-MWIB2, Olympus), a microscope (Olympus IX-71 Inverted Microscope) with a 4× objective and a digital camera (EOS Rebel T1i, Canon). The blue LED, filter cubes and digital camera were all mounted on the microscope. The filter cube contains a dichromatic mirror (DM505, Olympus) and an emission filter (BA510-IF, Olympus). The dichromatic mirror is positioned in the light path at a $45^{\circ}$ angle and selectively reflects wavelengths between 440 and $490 \mathrm{~nm}$, however, transmitting other wavelengths at the same time. The blue excitation given out by the blue LED reaches the dichromatic mirror and is reflected onto PCR mixture through the glass layer of PCR chip. The SYBR green I (maximum absorption $=498$ $\mathrm{nm}$ ) binds to dsDNA. When excited by the blue light, a green fluorescence emission (maximum emission $=522 \mathrm{~nm}$ ) passes through the glass layer, the dichromatic mirror and the emission filter and eventually arrives at the digital camera. The emission filter is long pass filter, which allows only light of wavelengths greater than $510 \mathrm{~nm}$ to reach the digital camera. The emission filter effectively prevents excitation light wavelengths either reflecting from the PCR chip or successfully traversing the dichromatic mirror from reaching the digital camera.

\subsection{PCR Components Optimization}

We chose PCR components and optimized conditions for DNA amplification on the microfluidic chip. Our objective was to have a low $T_{d}$ along with a small difference between the $T_{d}$ and $\mathrm{T}_{\mathrm{a}}$. To that end, we took into consideration the PCR components and their concentrations (see supporting information). We tested cytomegalovirus (CMV) primer pairs CMV368F \& CMV409R (71 bp) and CMV74F \& CMV409R (364 bp) with four different polymerases and their corresponding buffers (Supplemental Figure S2). On bench PCR cycler the SpeedStar performed well both in amplifying shorter (71 bp) and longer (364 bp) DNA fragments under same cycling conditions (extension time 20 seconds). For the PCR reactions, we chose primers of $24-30$ bases in length (Table 1). 
pEGFP-C1 vector (GenBank accession \#: U55763; total size: $4.731 \mathrm{kbp}$ ) was purchased from Clontech. Primers were selected using FastPCR software (PrimerDigital, Finland) (Kalendar et al. 2009). Size, $T_{m}$ and GC\% values of primers and PCR products were calculated using NetPrimer (Premier Biosoft International, USA).

The PCR consisted of the following components at their final concentrations: $0.75 \mu \mathrm{M}$ primers (Life Technologies), $3.5 \mathrm{mM} \mathrm{MgCl}_{2}$ (KapaBiosystems), $0.2 \mathrm{mM}$ dNTP (Takara Bio Inc.), up to 0.2

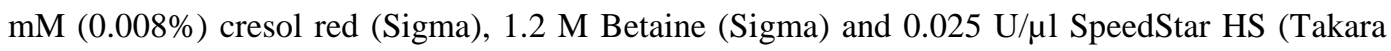
Bio Inc.).

For the purposes of viral sequence detection, we serially diluted plasmid vector so as to have 10 000, 100000 and 1 million vector molecules in one microliter. We designed primers for the CMV virus and SRY gene sequences (Table 1). Unstimulated whole-saliva samples were collected by passive drool. One microliter of saliva was used in a $20 \mu$ PCR reaction.

The bench thermocycler employed was MyGenie 96 Gradient Thermal Block (Bioneer Corporation), which uses Peltier elements for heating/cooling and has a ramping rate of $2.5^{\circ} \mathrm{C}$ per second (maximum).

PCR product detection was achieved by running samples in 3 - 4\% Agarose gel containing SYBR Safe DNA stain (Life Technologies) and by subsequent gel imaging. A DNA ladder (Life Technologies) was applied as a reference in estimating the sizes of DNA fragments. Quantification of band relative intensity was performed by ImageJ version 1.43 software (developed at the National Institutes of Health), subtracting the background and measuring the area of the peak. The obtained value for the band intensity was defined as relative band intensity (RBI). For on-chip detection, SYBR green I (Life Technologies, 10 000x), was diluted to 1x using TE buffer for the final concentration in PCR mixture.

\section{Results and discussion}

\section{1 $\mathrm{T}_{\mathrm{d}}$ and $\mathrm{T}_{\mathrm{a}}$ Optimization Using Viral Template DNA}

To detect the viral sequence of CMV, we employed a serial dilution of plasmid DNA with concentration of $10^{4}, 10^{5}$ and $10^{6}$ molecules in one microliter. Primers for CMV viral sequence were designed (Table 1 and Fig. S1). For the CMV368F \& CMV409R primer pair for the 71 bp the $\mathrm{T}_{\mathrm{a}}$ was optimized in the PCR using a 58 to $78^{\circ} \mathrm{C}$ gradient. The calculated oligo $\mathrm{T}_{\mathrm{m}}$ range was 78.80 to $80.29{ }^{\circ} \mathrm{C}$. Experiment was conducted using the SpeedStar HS polymerase. The PCR conditions were $94{ }^{\circ} \mathrm{C}$ for 20 seconds, followed by the gradient [58 - 78] ${ }^{\circ} \mathrm{C}$ for 20 seconds, and a total of 35 cycles. In the results, we observed that the optimal $\mathrm{T}_{\mathrm{a}}$ for the primer pair CMV368F \& CMV409R (71 bp) ranged from $<58{ }^{\circ} \mathrm{C}$ to the highest $\mathrm{T}_{\mathrm{a}}$ that could be used, $74.2{ }^{\circ} \mathrm{C}$ (Fig. $2 \mathrm{~A}$ and Table 2).

After we obtained the optimal $\mathrm{T}_{\mathrm{a}}$ value, we used the similar approach to determine the optimal $\mathrm{T}_{\mathrm{d}}$. We applied a $72-92{ }^{\circ} \mathrm{C}$ temperature gradient. Using the primer combination CMV368F \& 
CMV409R (71 bp), the DNA could be amplified from a $\mathrm{T}_{\mathrm{d}}>81^{\circ} \mathrm{C}$ with an optimal value of $\sim 90{ }^{\circ} \mathrm{C}$ (Fig. 2B and Table 2). The $\mathrm{T}_{\mathrm{a}}$ and $\mathrm{T}_{\mathrm{d}}$ can be chosen in such a way that even if the temperature is a few degrees lower or higher (in this example even over $16{ }^{\circ} \mathrm{C}$ range), the amplification product can still be observed.

We compared the conventional three-temperature PCR with two-temperature PCR used in our experiments. In the results, we could achieve a better control of final product with the twotemperature PCR, whereas some unspecific bands were generated in the three-temperature setup. Similar observations already have been made.(Dodson and Kant 1991) Higher annealing temperature in two-temperature PCR in comparison to three-temperature PCR contributes to the higher specificity.(Weighardt et al. 1993) The developed two-temperature PCR profile, thus, was deemed suitable for amplification of short DNA product, both in microfluidics and benchthermocycler PCR.

\subsection{PCR Using Unpurified Saliva as DNA Source}

After initial success in optimizing the $T_{a}$ and $T_{d}$ for selected primer pairs, we decided to use the same strategy to optimize the PCR to amplify DNA directly from whole saliva. Saliva is an ideal material for the diagnostics, as it is easy to collect, consists of $\sim 99 \%$ water, and contains cells (Dodds et al. 2005). There have been numerous diagnostics tests developed for PCR using saliva as the DNA source, tests both for viral diseases (Blackbourn et al. 1998; Crepin et al. 1998) and for bacterial infections (Eguchi et al. 2003). Here, we chose primer pairs from the SRY gene (GeneBank ID 4507224; Table 1 and Fig. S2). The primers were designed for a final PCR-product size of $93 \mathrm{bp}$. The $\mathrm{T}_{\mathrm{a}}$ was determined by fixing the $\mathrm{T}_{\mathrm{d}}$ to $94{ }^{\circ} \mathrm{C}$ and running the PCR with a $58-78$ ${ }^{\circ} \mathrm{C}$ annealing gradient. We could observe bands on the gel even for saliva collected more than a year ago and stored at $-20^{\circ} \mathrm{C}$. The results indicated the highest $\mathrm{T}_{\mathrm{a}}$ of $68.8^{\circ} \mathrm{C}$ when we could detect PCR products for the $93 \mathrm{bp}$ SRY fragment (Fig. 2C and Table 2). The calculated oligo $\mathrm{T}_{\mathrm{m}}$ ranged from 61.77 to $69.52{ }^{\circ} \mathrm{C}$. To determine the optimal $\mathrm{T}_{\mathrm{d}}$ temperature, we used a $74-94{ }^{\circ} \mathrm{C} \mathrm{T}_{\mathrm{d}}$ gradient while keeping the $\mathrm{T}_{\mathrm{a}}$ constant at $65^{\circ} \mathrm{C}$. In the results, we could see that the minimum $\mathrm{T}_{d}$ for which PCR products could be obtained for the 93 bp SRY fragment was $84.8^{\circ} \mathrm{C}$.

The $86{ }^{\circ} \mathrm{C} \mathrm{T}_{\mathrm{d}}$ is an advantageous alternative for chip PCR, as it is much lower than the usual 95 ${ }^{\circ} \mathrm{C}$. A low $\mathrm{T}_{\mathrm{d}}$ reduces chip-material interaction with PCR components and imparts the chip with enhanced heat transferability, minimizing the time and energy required to reach the necessary temperature. The difference between the $\mathrm{T}_{\mathrm{d}}$ and $\mathrm{T}_{\mathrm{a}}$ for the amplification on chip was only $19{ }^{\circ} \mathrm{C}$.

\subsection{Thermal Cycling Performance of Chip PCR}

Not like many other previously reported PCR device, where the PCR chamber and heater were usually integrated into one chip, (Lagally et al. 2001; Lagelly et al. 2004; Lee et al. 2004; Yoon et al. 2002; Zhao et al. 2003; Zhong et al. 2009) the heater and the PCR chamber of our PCR device can be easily assembled from individual component which is shown in Fig. 1, therefore, much 
flexible and changeable as needed. Once the heater chip is fabricated, it can be reused and only need to replace the PCR chamber for different purposes.

Fig. 3A shows a result of 16 thermal cycles for the ascendant as well as the descendent of temperature between $86^{\circ} \mathrm{C}$ and $67^{\circ} \mathrm{C}$ with time duration of $20 \mathrm{~s}$ for each. It can be seen from an inset in Fig. 3A that very rapid change of temperature can be achieved as fast as 1.5 second. The heating and cooling rate is as high as $12.7^{\circ} \mathrm{C} / \mathrm{s}$ and the accuracy of temperature control is less than $\pm 0.1^{\circ} \mathrm{C}$.

Since Si has a higher thermal conductivity $\left(149 \mathrm{Wm}^{-1} \mathrm{k}^{-1}\right)$ than glass $\left(1 \mathrm{Wm}^{-1} \mathrm{k}^{-1}\right)$. The inlet and outlet of the PCR chip were designed in Si layer instead of glass layer and a faster heat exchange (including heating and cooling) can be achieved between Pt heater and PCR mixture. Meanwhile, the inlet and outlet of the PCR chip can be sealed by the backside of heater chip as shown in Fig. 1C. We call it self-sealed layout since the PCR chip can be sealed without other materials such as mineral oil or other structures. The heater's temperature is always equal to Si layer in the PCR chip, so this design can prevent the leakage and condensation of water vapour on the inlet and outlet of PCR chip. To evaluate evaporative loss of this design, we need to know the volume of PCR mixture before and after PCR. We took two pictures (in Fig. 3B) of the PCR mixture in the PCR chamber before and after 35 thermal cycles $\left(86^{\circ} \mathrm{C}\right.$ for $20 \mathrm{~s}$ and $67{ }^{\circ} \mathrm{C}$ for $20 \mathrm{~s}$ ). Then we measured the area variation. After testing 10 chips, the evaporative loss was figured out to be only 6\% in average. During PCR, very few bubbles were observed due to the uniform thermal distribution (Fig. S6) and low $\mathrm{T}_{\mathrm{a}}$. The evaporation and bubble generation are two common negative effects for temperature controlling. Their minimization in turn will improve the PCR productivity.

\subsection{On-site Determination of Genetic Information}

We performed an On-Chip PCR using optimized two-temperature cycling process for the primer pair SRY93F \& SRY93R, where $\mathrm{T}_{\mathrm{d}}$ and $\mathrm{T}_{\mathrm{a}}$ are chosen to be respective $86{ }^{\circ} \mathrm{C}$ and $67{ }^{\circ} \mathrm{C}$ with duration time of 20 seconds of each for 35 cycles. PCR chambers used for the experiments here are $50 \mathrm{~mm}^{2}$ in area and $100 \mu \mathrm{m}$ in depth which can contain $5 \mu$ l reagents in volume. We injected $5 \mu$ of PCR mixture into the PCR chamber by pipet and run 35 thermal cycles (each cycle is set to $86{ }^{\circ} \mathrm{C} / 20 \mathrm{~s}$ and $67^{\circ} \mathrm{C} / 20 \mathrm{~s}$ ) using the optimized conditions. To verify the repeatability and specificity of our chip, we have tested it with various saliva sources. The electrophoresis gel result of bench machine and PCR chip is shown in Fig. 4A. Three PCR were done in three different PCR chips. The 93 bp DNA was successfully amplified both in chip and bench machine and there were no unspecific bands. From intensity of the two bands in lanes ii $\left(\mathrm{RBI}=1.7 \times 10^{4}\right)$ and iii $(\mathrm{RBI}=1.5 \times$ $10^{4}$ ), the amplification efficiency in chip is comparable as in bench machine. As expected no PCR product was observed in PCR using the female saliva due to lack of SRY gene. Negative control result indicates that there is no cross-contamination between the chips. These results indicate that, under optimized PCR conditions by utilizing raw saliva, genetic DNA can be successfully amplified in our PCR chip. 
In order to detect genetic information on-site, we designed an optical detection system shown in Fig. 1C, which can detect dsDNA by the fluorescence intensity. For optical detection in chip, we reduced the volume to $1.25 \mu \mathrm{l}$ with different PCR chamber where the height and area were reduced to $50 \mu \mathrm{m}$ and $25 \mathrm{~mm}^{2}$, respectively. We have tested 6 saliva samples collected from 3 male (Sample 1-3) and 3 female (Sample 4-6) volunteers. After PCR was performed in chip, we took the fluorescence image in a dark-room and exposure time was set to $1 / 4$ second. We used ImageJ software to measure the mean fluorescence intensity (MFI) of 50 pixels $\times 50$ pixels (white dash square in the centre of PCR chamber in Fig. 4B). The results are plotted in Fig. 4B. Two insets in Fig. 4B show the fluorescence images tested with male and female saliva, respectively. We can see clearly that there is a difference in fluorescence intensity between two images: the male one $(\mathrm{MFI}=17.7)$ is brighter than the female one $(\mathrm{MFI}=9.0)$ due to the amplified target DNA.

\section{Conclusions}

Successful DNA amplification and detection on chip depends on the optimization of many parameters including primers design, $T_{a}$ and $T_{d}$. We demonstrate that for PCR primer pair and two-temperature PCR, $T_{a}$ can be optimized first, following with $T_{d}$ optimization. Si and glass in PCR chip can be easily replaced to cheaper materials such as low cost polymer since the PCR chip is independent from the two functional systems. The PCR chip was directly combined by the heater chip avoiding the unnecessary complicated structure. This self-sealed design has not only a very high efficiency to prevent evaporation loss of reagents but also easy to handle. By using such design, the faster PCR with less than 25 minutes can be achieved. On-site testing for gene identification with raw saliva has been realized by fluorescence methodology which provides a promising prototype for developing PCR-based molecular POCT handheld device.

Acknowledgements The authors acknowledge the financial support provided by the Hong Kong Research Grants Council Grant No. HKUST 603608. This publication is based on work partially supported by Award No. SA-C0040/UK-C0016 made by King Abdullah University of Science and Technology (KAUST).

\section{References}

R.C. Anderson, X. Su, G.J. Bogdan, J. Fenton, Nucleic Acids Res. 28 (2000)

D.J. Blackbourn, E.T. Lennette, J. Ambroziak, D.V. Mourich, J.A. Levy, J. Infect. Dis. 177, 213

Chen Z, Mauk MG, Wang J, Abrams WR, Corstjens PLAM, Niedbala RS, Malamud D, Bau HH

Ann New York Acad Sci 1098, 429 (2007)

P. Crepin, L. Audry, Y. Rotivel, A. Gacoin, C. Caroff, H. Bourhy, J. Clin. Microbiol. 36, 1117

(1998) 
A.S. Daar, H. Thorsteinsdóttir, D.K. Martin, A.C. Smith, S. Nast, P.A. Singer, Nat. Genet. 32, 229 (2002)

M. W. J. Dodds, D.A. Johnson, C.-. Yeh, J. Dent. 33, 223 (2005)

L.A. Dodson, J.A. Kant, Mol. Cell. Probes 5, 21 (1991)

J. Eguchi, K. Ishihara, A. Watanabe, Y. Fukumoto, K. Okuda, Oral Microbiol. Immunol. 18, 156 (2003)

R. Kalendar, D. Lee, A.H. Schulman, Genes Genomes Genomics 3, 1 (2009)

J. Khandurina, T.E. McKnight, S.C. Jacobson, L.C. Waters, R.S. Foote, J.M. Ramsey, Anal. Chem. 72, 2995 (2000)

E.T. Lagally, C.A. Emrich, R.A. Mathies, Lab Chip 1, 102 (2001)

E.T. Lagally, P.C. Simpson, R.A. Mathies, Sens Actuators, B Chem 63, 138 (2000)

E.T. Lagelly, J.R. Scherer, R.G. Blazej, N.M. Toriello, B.A. Diep, M. Ramchandani, G.F. Sensabaugh, L.W. Riley, R.A. Mathies, Anal. Chem. 76, 3162 (2004)

D.-. Lee, S.H. Park, H. Yang, K.-. Chung, T.H. Yoon, S.-. Kim, K. Kim, Y.T. Kim, Lab Chip 4, 401 (2004)

K.-. Lien, C.-. Liu, P.-. Kuo, G.-. Lee, Anal. Chem. 81, 4502 (2009)

M. Mahalanabis, J. Do, H. Almuayad, J.Y. Zhang, C.M. Klapperich, Biomed. Microdevices 12, 353 (2010)

D.P.K. Ng, D. Koh, S.G.L. Choo, V. Ng, Q. Fu, Clin. Chim. Acta 343, 191 (2004)

S.J. Park, J.Y. Kim, Y.G. Yang, S.H. Lee, J. Forensic Sci. 53, 335 (2008)

N. Ramalingam, H.-. Liu, C.-- Dai, Y. Jiang, H. Wang, Q. Wang, K. M Hui, H.-. Gong, Biomed. Microdevices 11, 1007 (2009)

S.K. Sia, L.J. Kricka, Lab Chip 8, 1982 (2008)

F. Wang, M. Yang, M.A. Burns, Lab Chip 8, 88 (2008)

L.C. Waters, S.C. Jacobson, N. Kroutchinina, J. Khandurina, R.S. Foote, J.M. Ramsey, Anal. Chem. 70, 158 (1998)

F. Weighardt, G. Biamonti, S. Riva, Genome Res. 3, 77 (1993)

P. Yager, T. Edwards, E. Fu, K. Helton, K. Nelson, M.R. Tam, B.H. Weigl, Nature 442, 412 (2006)

S.S.W. Yeung, T.M.H. Lee, I.-. Hsing, Anal. Chem. 80, 363 (2008)

D.S. Yoon, Y.-. Lee, Y. Lee, H.J. Cho, S.W. Sung, K.W. Oh, J. Cha, G. Lim, J. Micromech. Microeng. 12, 813 (2002)

Z. Zhao, Z. Cui, D. Cui, S. Xia, Sens. Actuat. A Phys. 108, 162 (2003)

R. Zhong, X. Pan, L. Jiang, Z. Dai, J. Qin, B. Lin, Electrophoresis 30, 1297 (2009) 


\section{Figures}

Fig. 1

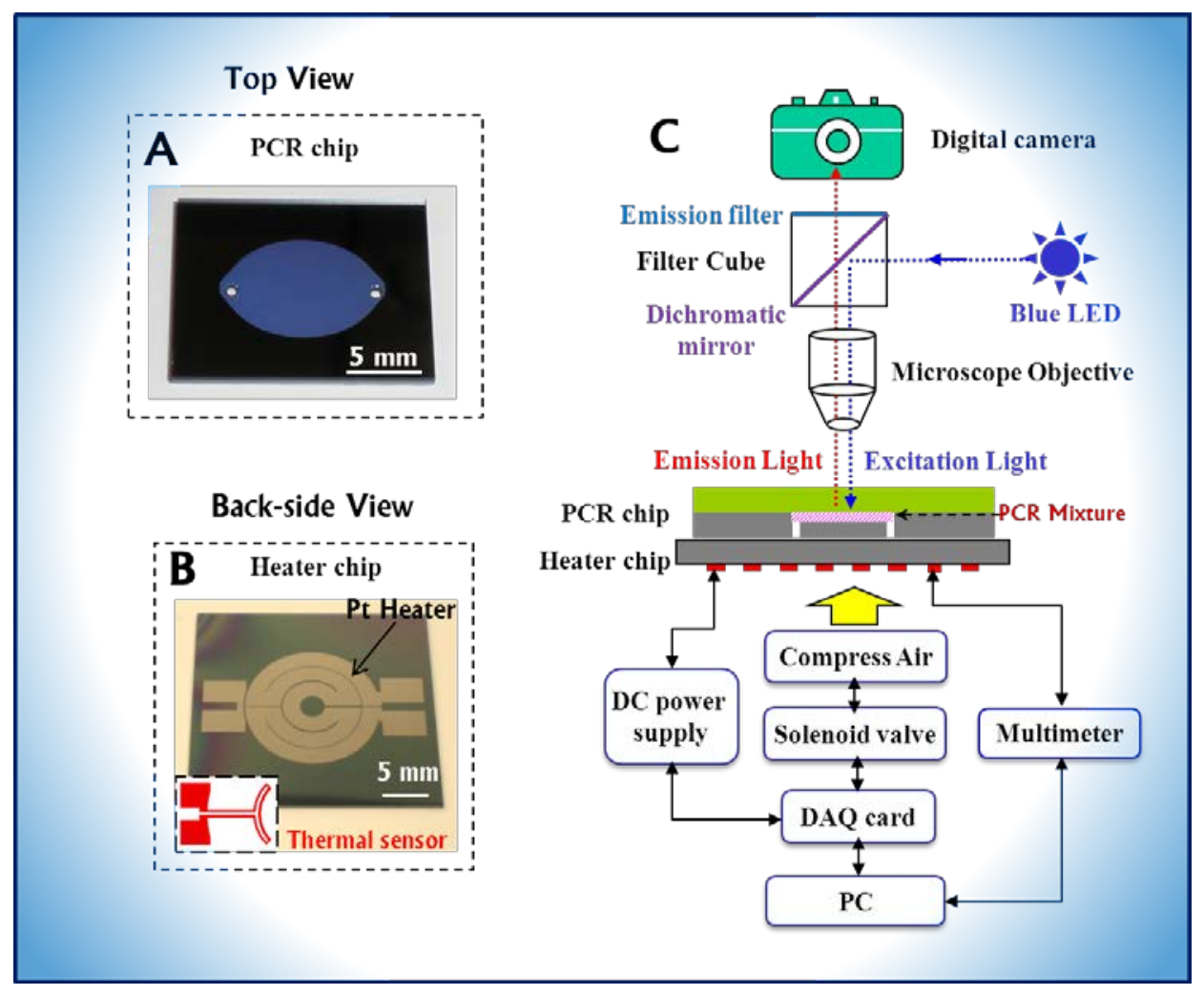


Fig. 2

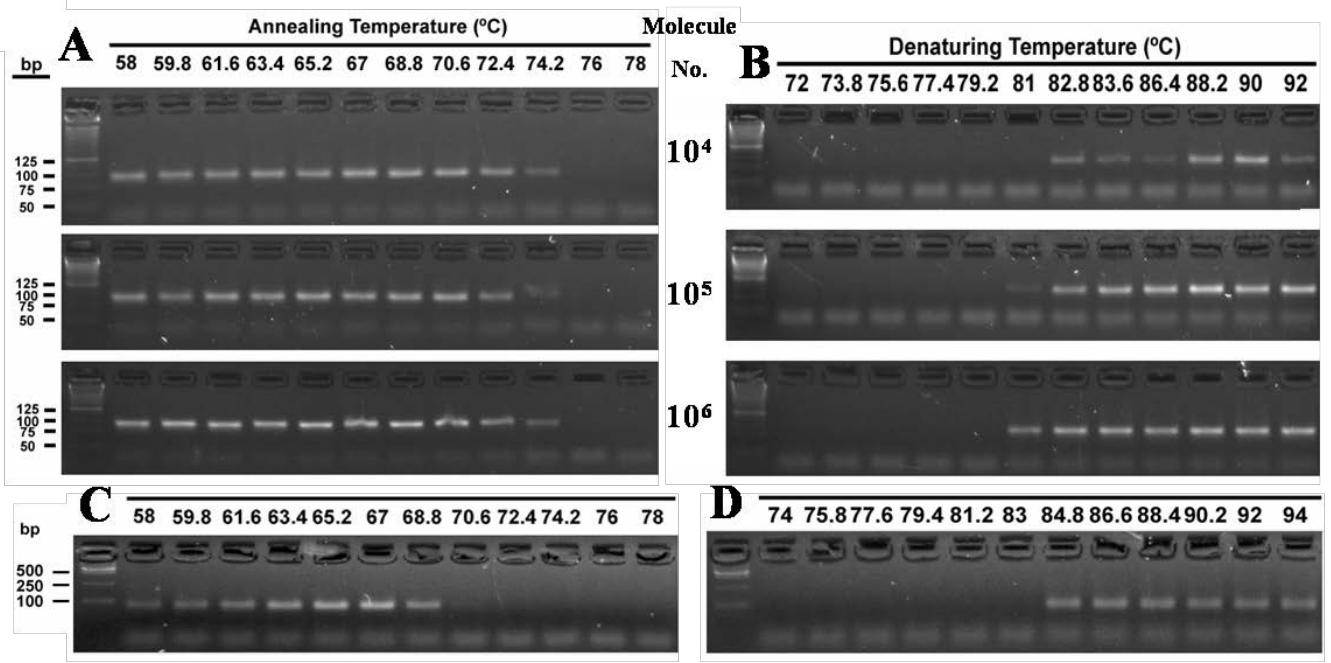


Fig. 3

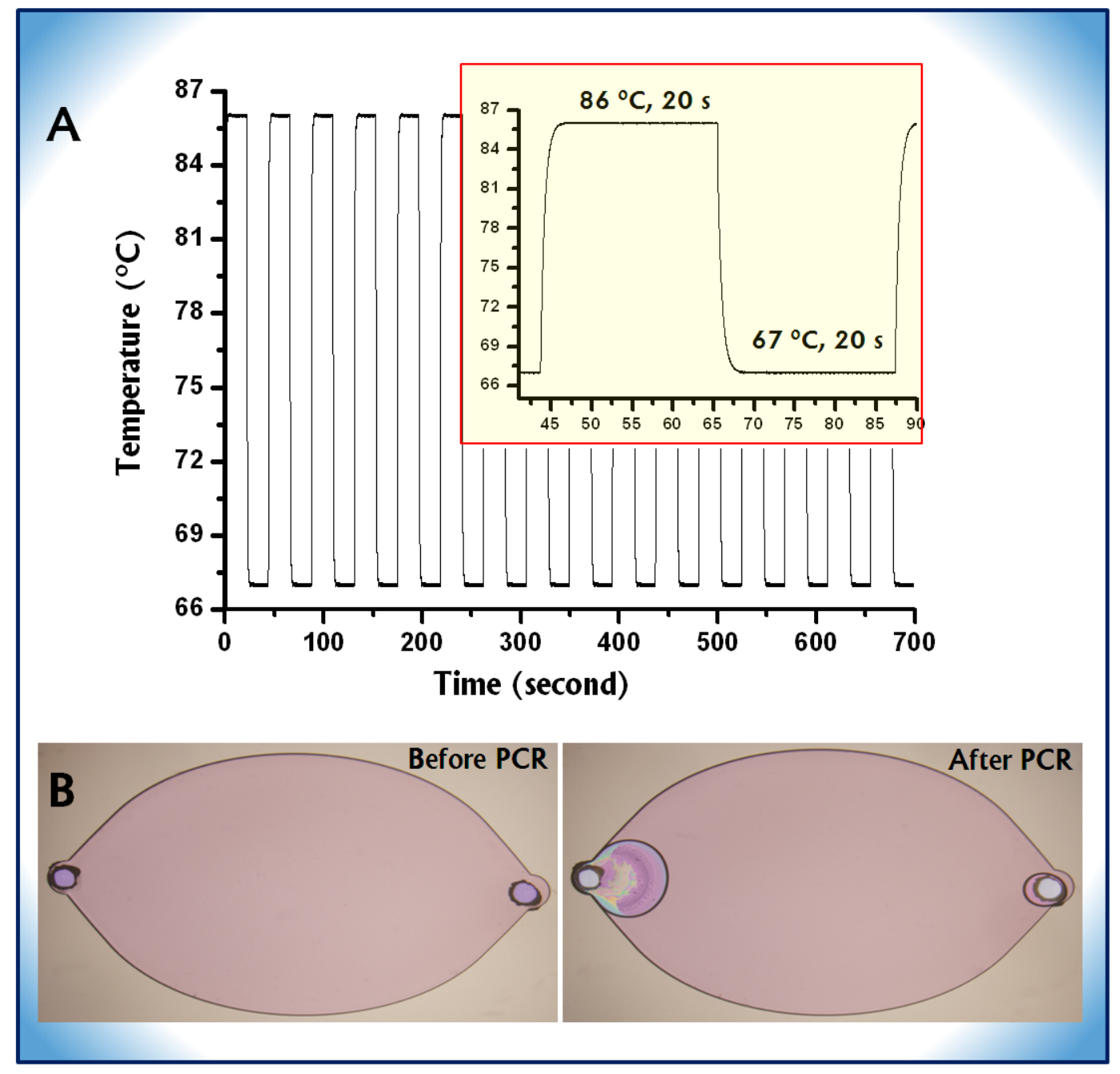


Fig. 4

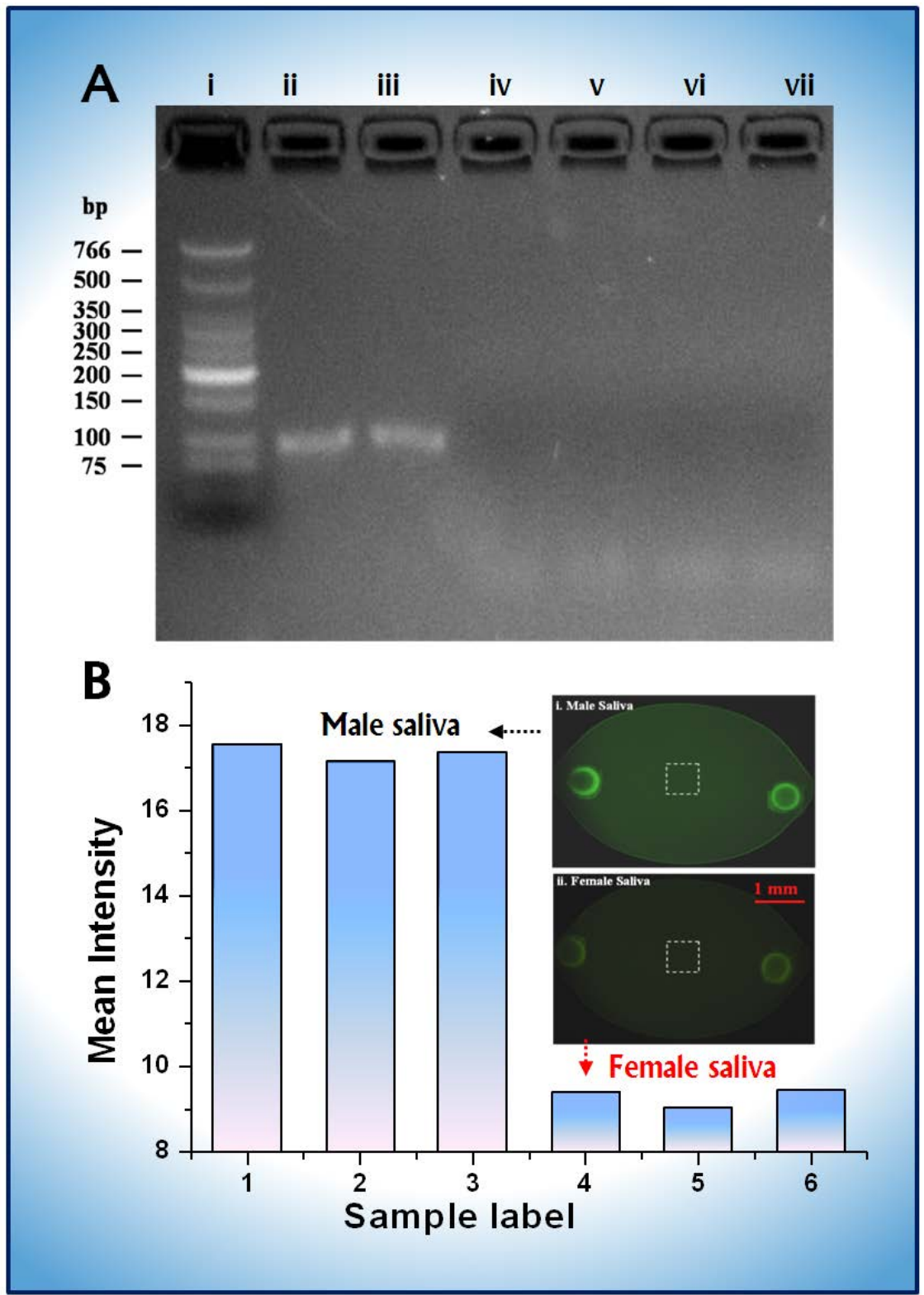




\section{Figure Captions}

Fig. 1 PCR devices layout (preferred position: section 2.1)

A. Top view of PCR chip; B. Back-side view of heater chip; C. Upper panel is optical detection system. Central panel is chip layout of self-sealed. PCR chip was put on the backside of heater chip after PCR mixture was injected into PCR chamber. Lower panel is temperature control system connected to heater chip.

Fig. 2. PCR condition optimizations (preferred position: section 3.1)

A \& B. The $T_{d}$ and $T_{a}$ optimization using primer pair CMV368F \& CMV409R for the $71 \mathrm{bp}$ amplicon. Here the DNA can be amplified from a $\mathrm{T}_{\mathrm{d}}>81^{\circ} \mathrm{C}$ with the optimal value of $\sim 90^{\circ} \mathrm{C}$. Optimal $\mathrm{T}_{\mathrm{a}}$ ranges from $<58{ }^{\circ} \mathrm{C}$ to the highest $\mathrm{T}_{\mathrm{a}}$ that can be used in this case, $74.2{ }^{\circ} \mathrm{C}$; $\mathrm{The}_{\mathrm{a}}(\mathrm{A})$ and $\mathrm{T}_{\mathrm{d}}(\mathrm{B})$ optimization using primer pair SRY93F \& SRY93R for the 93 bp amplicon. PCR amplification from raw saliva is successful with the highest $\mathrm{T}_{\mathrm{a}}$ of $68.8{ }^{\circ} \mathrm{C}$ and minimum $\mathrm{T}_{\mathrm{d}}$ of 84.8 ${ }^{\circ} \mathrm{C}$. C \& D. The $\mathrm{T}_{\mathrm{a}}(\mathrm{C})$ and $\mathrm{T}_{\mathrm{d}}(\mathrm{D})$ optimization using primer pairs SRY93F \& SRY93R for the 93 bp amplicon. PCR amplification from raw saliva is successful with the highest $\mathrm{T}_{\mathrm{a}}$ of $68.8{ }^{\circ} \mathrm{C}$ and minimum $\mathrm{T}_{\mathrm{d}}$ of $84.8^{\circ} \mathrm{C}$.

Fig. 3 Thermal cycling performances in chip (preferred position: section 3.3)

A. 16 thermal cycling result achieved by the temperature system. The inset is one thermal cycling for $86^{\circ} \mathrm{C}$ and $67^{\circ} \mathrm{C}$ with time duration of 20 s; B. Evaporative loss comparison.

Fig. 4 PCR results in chip (preferred position: section 3.4)

A. Electrophoresis gel result: i. DNA ladder, ii. male saliva in bench machine, iii. male saliva in chip, iv. female saliva in bench machine, v. female saliva in chip, vi. negative control in bench machine, vii. negative control in chip; B. The mean fluorescence intensity of PCR results using male (sample 1 3) and female (sample $4 \sim 6$ ) saliva as template. i. male saliva, ii. female saliva. The two inset are fluorescence images obtained by the optical detection system after PCR: i. male saliva, ii. female saliva. 


\section{Tables}

Table 1: Primer sequence and characteristics. (preferred position: section 2.4)

\begin{tabular}{ccclccc} 
DNA source & Region & Primers & \multicolumn{1}{c}{ Sequence } & Length, bp & $\mathrm{T}_{\mathrm{m}},{ }^{\circ} \mathrm{C}$ & $\mathrm{GC},{ }^{\circ}$ \\
Saliva & SRY & SRY93F & ATAAGTATCGACCTCGTCGGAAG & 23 & 61.77 & 47.80 \\
Saliva & SRY & SRY93R & GCACTTCGCTGCAGAGTACCGAAG & 24 & 69.52 & 58.30 \\
Plasmid vector & CMV & CMV74F & ACGGTAAATGGCCCGCCTGGCTGA & 24 & 77.84 & 62.50 \\
Plasmid vector & CMV & CMV368F & ATGCGGTTTTGGCAGTACATCAATGGGCGT & 30 & 80.29 & 50.00 \\
Plasmid vector & CMV & CMV409R & GGGTGGAGACTTGGAAATCCCCGTGAGTCA & 30 & 78.80 & 56.67
\end{tabular}

Table 2: Oligo pairs and experimental results. (preferred position: section 3.1)

$\begin{array}{cccccc}\text { Oligo 1 } & \text { Oligo 2 } & \text { Product, bp } & \mathrm{T}_{\mathrm{a}}[\min -\max ] & \mathrm{T}_{\mathrm{d}}[\mathrm{min}] & \text { Region GC, \% } \\ \text { CMV409R } & \text { CMV368F } & 71 & 71[<58.0-74.2] & 90[>81.0] & 53.5 \\ \text { SRY93F } & \text { SRY93R } & 93 & 67[<58.0-68.8] & 85[884.8] & 54.8\end{array}$

